\title{
The Relationship of Myometrial Invasion Between Other Prognostic Parameters in Endometrial Cancer
}

\author{
Mehmet Sait BAKIR, Ali Emre TAHAOĞLU1, Emre ERDOĞDU1, Cem DANE² \\ Diyarbakır, Turkey
}

\begin{abstract}
OBJECTIVE: The aim of this study is to investigate the relationship between deep myometrial invasion and other prognostic factors in endometrial cancer. Recurrence rates, disease free survival and overall survival rates were evaluated in endometrial cancer patients with $M l>50 \%$.

STUDY DESIGN: A total of 132 patients with endometrial cancer who underwent surgical treatment between 2001 and 2011 were identified. Demographic, clinicopathological, surgical/adjuvant treatment and follow-up data were extracted.

RESULTS: Pelvic lymph node invasion ratio was $28,9 \%$ and para-aortic lymph node invasion ratio was $15,5 \%$ in patients with myometrial invasion is greater than $50 \%$. Other prognostic factors especially lympho-vascular space invasion and pelvic/para-aortic lymph node metastasis were significantly higher when myometrial invasion is above $50 \%$ and also there was significant difference in recurrence rates, overall survival and disease free survival rates between patients with superficial and deep myometrial invasion $(p<0.05)$.
\end{abstract}

CONCLUSION: Myometrial invasion is an important prognostic parameter and can be determined intraoperatively to decide whether to perform pelvic and para-aortic lymph node dissection.

Keywords: Endometrial cancer, Myometrial invasion, Overall survival

Gynecol Obstet Reprod Med 2017;23(3):158-162

\section{Introduction}

Endometrial cancer is the most common gynecologic malignancy in developed countries and survival in endometrial carcinoma depends on many factors (1). Most women with endometrial cancer in early stage have a good prognosis with an overall survival (OS) rates up to $90 \%$ (2). Especially in early stage of endometrial cancer, the necessity of pelvic and/or para-aortic lymphadenectomy is still uncertain. Lymphadenectomy is often omitted if the surgeon feels that

\footnotetext{
${ }^{1}$ Health Sciences University Gazi Yasargil Research and Training Hospital, Diyarbakır,

${ }^{2}$ Haseki Research and Training Hospital, Istanbul Address of Correspondence: Ali Emre Tahaoğlu Health Sciences University, Gazi Yasargil Research and Training Hospital, Diyarbakır alyemre@yahoo.com

Submitted for Publication: $\quad 30.11 .2016$ Accepted for Publication: $\quad 03.04 .2017$
}

\begin{tabular}{|c|c|}
\hline \multicolumn{2}{|c|}{ Access this article online } \\
\hline $\begin{array}{c}\text { Quick Response Code: } \\
\text { व }\end{array}$ & Website: www.gorm.com.tr \\
\hline 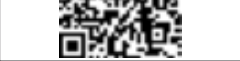 & DOI:10.201613/GORM.2016.648 \\
\hline
\end{tabular}

How to cite this article: Bakır MS. Tahaoğlu AE. Erdoğdu E. Dane C. The Relationship of Myometrial Invasion Between Other Prognostic Parameters in Endometrial Cancer. Gynecol Obstet Reprod Med 2017;23(3):158-162 the risk of lymph node metastasis is less likely on preoperative and intraoperative findings (3). However, it is generally agreed that patients with any of these risk factors including serous or clear cell histology, grade 3 tumors, tumor size $>2$ $\mathrm{cm}$, deep myometrial invasion would have a high risk of nodal metastasis and should be candidates for lymphadenectomy (4). In addition, age, histologic subtype, tumor grade, FIGO stage and myometrial invasion are reported to be the most important predictors of OS and recurrence free survival (5-8). In the present study we discussed the relationship between myometrial invasion and other prognostic parameters and calculated OS, disease free survival (DFS) and recurrence rates in regards of myometrial invasion degree.

\section{Material and Method}

A total of 132 patients with endometrial cancer who underwent surgical treatment at Haseki Research and Training Hospital, Istanbul between 2001 and 2011 were identified. Local Institution's Ethics committee approval was received. All patients underwent staging surgery including total abdominal hysterectomy (TAH), bilateral salpingo-oophorectomy (BSO), pelvic and para-aortic lymphadenectomy, partial or total omentectomy and peritoneal washing cytology. Patients with incomplete surgery were excluded. Histologic type, grade, lymphovascular space invasion (LVSI), myometrial invasion, pelvic $+/$ - para-aortic lymph node metastasis, recurrence, peritoneal washing cytology were also noted. All pa- 
tients with high risk factors for recurrence received either adjuvant radiotherapy (RT). Stage 4 patients and patients with incomplete data were excluded from the analysis.

Demographic, clinicopathological, surgical/adjuvant treatment and follow-up data were extracted from Hospital's annual reports by an investigator. According to pathology reports, patients who had myometrial invasion above $50 \%$ were evaluated with other prognostic factors as lympho-vascular space invasion (LVSI), lymph node metastasis, cervical involvement, omental involvement and further recurrence, DFS and OS rates were calculated with Kaplan-Meier statistical analysis.

Statistical analysis was performed by NCSS (Number Cruncher Statistical System) 2007 Statistical Software (Utah, USA). Descriptive statistics, chi-square and $\mathrm{T}$ test were used for analysis; and effect of myometrial invasion on survival rates was investigated with Kaplan Meier and Log Rank test. The $p$ value of $<0.05$ was considered significant.

\section{Results}

A total of 132 patients were included in the study. Demographic characteristics are shown in table 1. Any of the preoperative features of patients was not statistically significant (except gravidity and parity) between patients who had myometrial invasion is above and below $50 \%$.

All parameters including; peritoneal washing cytology, serosal invasion, LVSI, cervical glandular and stromal invasion, pelvic and paraaortic lymph node invasion and omental invasion; were significantly higher in cases who had myometrial invasion more than $50 \%$ (Table 2).

Overall survival and DFS rates were significantly lower in patients with deep myometrial invasion, compared to patients with superficial my- ometrial invasion, as well as recurrences were significantly higher in patients with deep myometrial invasion. (Table 3).

Disease free survival and OS were statistically lower in patients who had-myometrial invasion- above 50\% when a log rank test was performed $(\mathrm{p}<0.05)$ (Figure $1-2)$.

Table 1: Descriptive characteristics

\begin{tabular}{|c|c|c|c|c|c|c|}
\hline & & \multicolumn{2}{|c|}{$\begin{array}{l}\text { Myometrial } \\
\text { invasion } \\
<\% 50 \text { n:87 }\end{array}$} & \multicolumn{2}{|c|}{$\begin{array}{l}\text { Myometrial } \\
\text { invasion } \\
\text { >\%50 n:45 }\end{array}$} & $p$ \\
\hline \multicolumn{2}{|l|}{ Age } & \multicolumn{2}{|c|}{$58.8 \pm 9.9$} & \multicolumn{2}{|c|}{$59.1 \pm 10.6$} & NS \\
\hline Gravida & & \multicolumn{2}{|c|}{$4.9 \pm 2.9$} & \multicolumn{2}{|c|}{$3.9 \pm 1.9$} & $<0.05$ \\
\hline Parity & & \multicolumn{2}{|r|}{$3.9 \pm 2.4$} & \multicolumn{2}{|r|}{$2.8 \pm 1.9$} & $<0.05$ \\
\hline Length & & \multicolumn{2}{|c|}{$158.8 \pm 7.1$} & \multicolumn{2}{|c|}{$158.2 \pm 6.4$} & NS \\
\hline Weight & & \multicolumn{2}{|c|}{$86.4 \pm 15.5$} & \multicolumn{2}{|c|}{$84.9 \pm 14.4$} & NS \\
\hline BMI(body mass index) & & \multicolumn{2}{|c|}{$34.3 \pm 6.4$} & \multicolumn{2}{|c|}{$34.2 \pm 7.1$} & NS \\
\hline \multirow{2}{*}{ Menopause } & - & 18 & $20,6 \%$ & 8 & $17,7 \%$ & \multirow{2}{*}{ NS } \\
\hline & + & 69 & $79,3 \%$ & 37 & $82,2 \%$ & \\
\hline \multirow{2}{*}{$\begin{array}{l}\text { Family history of } \\
\text { endometrium cancer }\end{array}$} & - & 86 & $98,8 \%$ & 44 & $97,7 \%$ & \multirow{2}{*}{ NS } \\
\hline & + & 1 & $1,15 \%$ & 1 & $2,22 \%$ & \\
\hline \multirow{2}{*}{ Diabetes mellitus } & - & 64 & $73,5 \%$ & 34 & $75,5 \%$ & \multirow{2}{*}{ NS } \\
\hline & + & 23 & $26,4 \%$ & 11 & $24,4 \%$ & \\
\hline \multirow{2}{*}{ Hypertension } & - & 43 & $49,4 \%$ & 21 & $46,6 \%$ & \multirow{2}{*}{ NS } \\
\hline & + & 44 & $50,5 \%$ & 24 & $53,3 \%$ & \\
\hline
\end{tabular}

Table 2: Relationship between myometrial invasion and other prognostic factors

\begin{tabular}{|c|c|c|c|c|c|c|c|c|}
\hline \multirow{3}{*}{\begin{tabular}{|l} 
\\
$\begin{array}{l}\text { Peritoneal washing } \\
\text { cytology }\end{array}$ \\
\end{tabular}} & & & \multicolumn{3}{|c|}{$\begin{array}{l}\text { Myometrial } \\
\text { invasion } \\
<\% 50 \text { n:87 }\end{array}$} & \multicolumn{2}{|c|}{$\begin{array}{l}\text { Myometrial } \\
\text { invasion } \\
>\% 50 \text { n:45 }\end{array}$} & \multirow{3}{*}{$\begin{array}{c}p \\
<0.05\end{array}$} \\
\hline & \multicolumn{2}{|l|}{-} & \multicolumn{2}{|c|}{84} & \multirow{2}{*}{\begin{tabular}{|c|}
$96.5 \%$ \\
$3.4 \%$ \\
\end{tabular}} & \multirow{2}{*}{\begin{tabular}{c|}
39 \\
6
\end{tabular}} & \multirow{2}{*}{\begin{tabular}{|l|}
$86.6 \%$ \\
$13.3 \%$
\end{tabular}} & \\
\hline & + & & & & & & & \\
\hline \multirow{2}{*}{ Uterine serosal invasion } & \multicolumn{2}{|l|}{ - } & \multicolumn{2}{|c|}{87} & $100 \%$ & 35 & $77.7 \%$ & \multirow{2}{*}{$<0.05$} \\
\hline & \multicolumn{2}{|l|}{+} & \multicolumn{2}{|c|}{0} & $0 \%$ & 10 & $22.2 \%$ & \\
\hline \multirow{2}{*}{$\begin{array}{l}\text { Lympho-vascular space } \\
\text { invasion }\end{array}$} & \multicolumn{2}{|l|}{-} & \multicolumn{2}{|c|}{78} & $89.6 \%$ & 19 & $42.2 \%$ & \multirow{2}{*}{$<0.05$} \\
\hline & \multicolumn{2}{|l|}{+} & \multicolumn{2}{|c|}{9} & $10.3 \%$ & 26 & $57.7 \%$ & \\
\hline \multirow{3}{*}{ Grade } & Grade 1 & 19 & $76 \%$ & 33 & $58.9 \%$ & 13 & $31.7 \%$ & \multirow{3}{*}{$<0.05$} \\
\hline & Grade 2 & 4 & $16 \%$ & 19 & $33.9 \%$ & 15 & $36.5 \%$ & \\
\hline & Grade 3 & 2 & $8 \%$ & 4 & $7.1 \%$ & 13 & $31.7 \%$ & \\
\hline \multirow{2}{*}{ Cervical stromal invasion } & \multicolumn{2}{|l|}{-} & \multicolumn{2}{|c|}{83} & $95.4 \%$ & 31 & $68.8 \%$ & \multirow{2}{*}{$<0.05$} \\
\hline & \multicolumn{2}{|l|}{+} & \multicolumn{2}{|c|}{4} & $4.6 \%$ & 14 & $31.1 \%$ & \\
\hline \multirow{2}{*}{ Pelvic lymph node } & \multicolumn{2}{|l|}{-} & \multicolumn{2}{|c|}{85} & $97.7 \%$ & 32 & $71.1 \%$ & \multirow{2}{*}{$<0.05$} \\
\hline & \multicolumn{2}{|l|}{+} & \multicolumn{2}{|c|}{2} & $2.3 \%$ & 13 & $28.8 \%$ & \\
\hline \multirow{2}{*}{ Para-aortic lymph node } & - & & & & $100 \%$ & 38 & $84.4 \%$ & \\
\hline & + & & & & $0 \%$ & 7 & $15.5 \%$ & $<0.05$ \\
\hline & - & & & & $100 \%$ & 40 & $88.8 \%$ & \\
\hline Omentum invasion & + & & & & $0 \%$ & 5 & $11.1 \%$ & -0.05 \\
\hline
\end{tabular}


Table 3: Survival and recurrence rates of the patients

\begin{tabular}{|c|c|c|c|c|c|c|}
\hline \multirow{3}{*}{ Recurre } & \multirow[b]{2}{*}{$(-)$} & \multicolumn{2}{|c|}{$\begin{array}{c}\text { Myometrial invasion } \\
<\% 50 \mathrm{n}: 87\end{array}$} & \multicolumn{2}{|c|}{$\begin{array}{c}\text { Myometrial invasion } \\
>\% 50 \mathrm{n}: 45\end{array}$} & $p$ \\
\hline & & 79 & $90.8 \%$ & 20 & $44.4 \%$ & \multirow[t]{2}{*}{0.001} \\
\hline & $(+)$ & 8 & $9.2 \%$ & 25 & $955.5 \%$ & \\
\hline \multicolumn{2}{|c|}{ Follow up (month) (median- IQR) } & \multicolumn{2}{|c|}{$86(65-106)$} & \multicolumn{2}{|c|}{$68(42,5-98)$} & $<0.05$ \\
\hline \multicolumn{2}{|c|}{ OS (month) (median- IQR) } & \multicolumn{2}{|c|}{$86(65-106)$} & \multicolumn{2}{|c|}{$68(42,5-98)$} & $<0.05$ \\
\hline \multicolumn{2}{|c|}{ DFS (month) (median- IQR) } & \multicolumn{2}{|c|}{$80(65-105)$} & \multicolumn{2}{|c|}{$45(12,9-76,5)$} & $<0.001$ \\
\hline
\end{tabular}

OS: Overall survival, DFS: Disease free survival

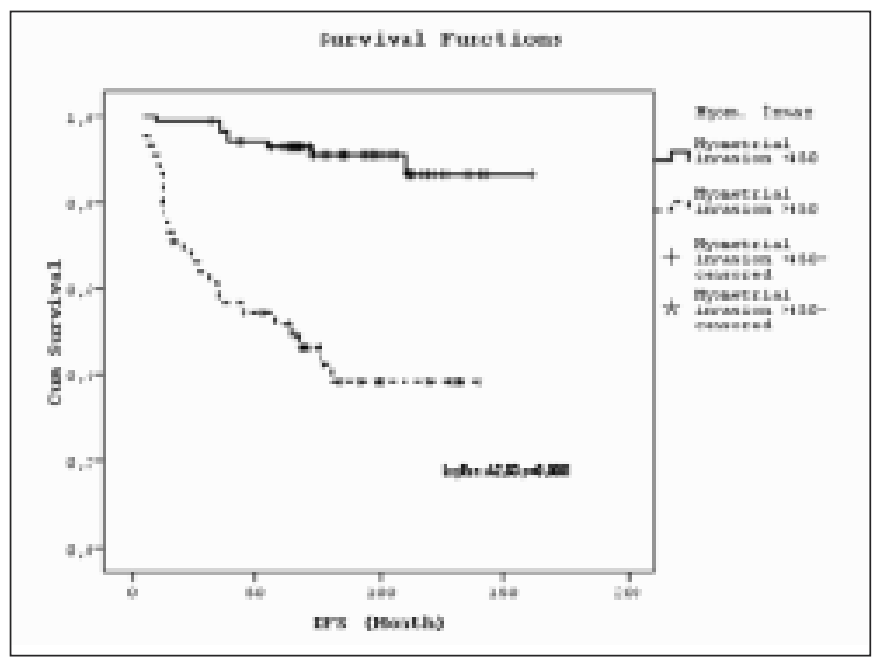

Figure 1: Disease free survival rates

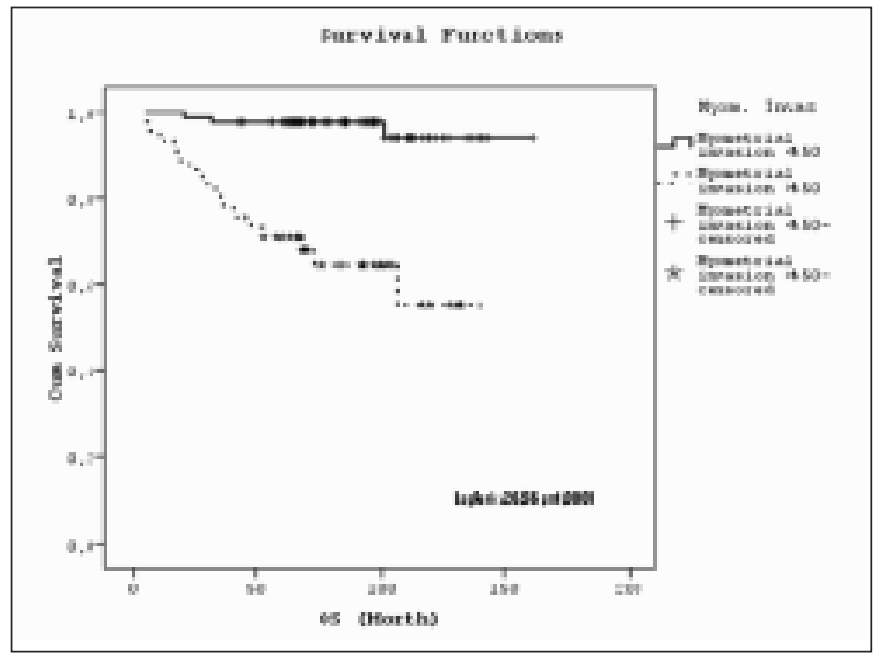

Figure 2: Overall survival rates

\section{Discussion}

Endometrial cancer is the sixth most common cancer in women (9); fortunately, most of the cases are low grade, low stage endometrioid adenocarcinomas (10-11). Hence studies seeking to define subset of patients with low grade endometrioid adenocarcinoma who could most benefit from surgical staging (12-14). While complete surgical staging approach is recommended for endometrial cancer (15); some authors declared opposite that when considering the risk/benefit ratio, total lymphadenectomy is not recommended in low risk group (16). In women with deep myometrial invasion, uterine serosal invasion and lesions $>2 \mathrm{~cm}$ in size had statistically significant higher rate of retroperitoneal lymph nodes metastasis in comparison with lesions $<-2 \mathrm{~cm}$ in size (17). In our study when myometrial invasion is above $50 \%$, pelvic lymph node invasion was $28.89 \%$ and para-artic lymph nod invasion was $15.5 \%$. By that way greater than $50 \%$ myometrial invasion is significant for lymph node invasion $(\mathrm{p}<0.05)$. Myometrial invasion is a prognostic factor for extra uterine spread (18) and an important predictor for pelvic and para-aortic lymph node dissection.

Besides depth of myometrial invasion is an important prognostic factor and determination of myometrial invasion is essential to decide surgical staging and adjuvant treatment options (18). High grade histology and deep myometrial invasion are associated with significantly higher incidence of retroperitoneal nodal metastases $(17,19,20)$. Myometrial invasion is associated with other prognostic factors. In our study, myometrial invasion more than $50 \%$ is strongly associated with pelvic and paraaortic lymph node metastasis $(\mathrm{p}<0.05)$. Also, other prognostic values such as; peritoneal washing cytology, cervical stromal and gland invasion, LVSI, uterine serosal invasion and omental invasion were associated with deep myometrial invasion $(\mathrm{p}<0.05)$

We found when only myometrial invasion is above 50\%; the recurrence rate is $55.5 \%$ and both OS and DFS rates were significantly lower in patients with superficial myometrial invasion compared to patients with deep myometrial invasion is $(p<0.05)$. Age, histologic subtype, tumor grade, FIGO stage and myometrial invasion are the most important predictors of OS and DFS $(5,8)$. Myometrial invasion also changed the stage (21) and decision of adjuvant treatment (6)

In a study, the authors showed that deeply myometrial invasion predicts pelvic and para-aortic lymph node metastasis in $19 \%$ and $14 \%$ of patients respectively (22). Deep myometrial invasion, generally assessed intraoperatively, has been 
recognized as one of the most important predicting factors for nodal metastasis (21). Since myometrial invasion is a parameter that can be measured intraoperatively and guide the decision whether to perform staging (23). It is still unclear the operative assessment of myometrial invasion (24); however high frozen/permanent section should be taken into consideration for lymphadenectomy $(25,26)$.

Limitations of our study were, small number of cases and several team of surgeons who performed the surgery. Our study clearly demonstrates that; when myometrial invasion is identified pelvic and para-aortic lymphadenectomy should be performed.

In conclusion myometrial invasion is an important prognostic parameter and can be evaluated intraoperatively to decide whether to perform pelvic and para-aortic lymph node dissection.

\section{References}

1. Given D, Baka K, Kodak I, Stun C. Endometrial Cancer Evaluation of Diagnostics Treatment and Prognosis in 150 Patients. Gynecol Obstet Reprod Med 2012;18(1):21-5

2. Balasubramaniam G, Sushama s, Rasika B. Hospitalbased Study of Endometrial Cancer Survival in Mumbai, India. Asian Pacific J Cancer Prev 2013;14(2): 977-80.

3. Mahdi H, Jernigan A, Nutter B, Michener C, Rose PG. Lymph node metastasis and pattern of recurrence in clinically early stage endometrial cancer with positive lymphovascular space invasion. J Gynecol Oncol 2015;26(3): 208-13

4. McMeekin DS, Yashar C, Campos SM, Zaino RJ . Corpus: epithelial tumors. In: Barakat RR, Berchuck A, Markman M, Randall ME, editors. Principles and practice of gynecologic oncology. $6^{\text {th }}$ ed. Philadelphia:Lippincott Williams \& Wilkins 2013,661-714

5. Zaino Rj, Kurman RJ, Diana KL, Morrow CP. Pathologic models to predict outcome for women with endometrial adenocarcinoma: the importance of the distinction between surgical stage and clinical stage- a Gynecologic Oncology group study. Cancer 1996;77(6):1115-21

6. Creutzberg CL, Van Putten WL, Koper PC, Lybeert ML, Jobsen JJ, Wárlám-Rodenhuis CC, et. al. Surgery and postoperative radiotherapy versus surgery alone for patients with stage-1 endometrial carcinoma: multicenter randomised trial. PORTEC Study Group. Post Operative Radiation Therapy in Endometrial Carcinoma. Lancet 2000;355(9213):1404-11

7. Larson DM, Connor GP, Broste SK, Krawisz BR, Johnson KK. Prognostic significance of gross myometrial invasion with endometrial cancer. Obstet Gynecol 1996; 88(3):394-8

8. Prat J. Prognostic parameters of endometrial carcinoma. Hum Pathol 2004; 35(6):649-62
9. Ferlay J, Shin HR, Bray F, Forman D. Estimates of worldwide burden of cancer in 2008: GLOBOCAN 2008. Int J Cancer 2010;127(12):2893-917

10. Chan JK, Cheung MK, Hugh Wk, Osann K, Husain A, Teng NN, Kapp DS. Therapeutic role of lymph node resection in endometrioid corpus cancer. Cancer 2006; 107(8):1823-30

11. Chan Jk, Huahsi Wu, Cheung MK, Shin JY, Osann K, Kapp DS. The outcomes of 27,063 women with unstaged endometrioid uterine cancer. Gynecol Oncol 2007; $106(2): 282-88$

12. Bakkum-Gamez JN, Mariani A, Dowdy SC, Weaver AL, McGree ME, Cliby WA, Gostout BS, Stanhope CR, Wilson TO, Podratz KC. The impact of surgical guidelines and periodic quality assessment on the staging of endometrial cancer. Gynecol Oncol 2011;123(1):58-64

13. Mariani A, Dowdy SC, Cliby WA, Gostout BS, Jones MB, Wilson TO, Podratz KC. Prospective assessment of lymphatic dissemination in endometrial cancer: a paradigm shift in surgical staging. Gynecol Oncol 2008;109(1):11-8

14. Kwon JS, Mazgani M, Miller DM, Ehlen T, Heywood M, McAlpine JN, Finlayson SJ, Plante M, Stuart GC, Carey MS. The significance of surgical staging in intermediaterisk endometrial cancer. Gynecol Oncol 2011;122(1):50-4

15. Wright JD, Barrena Medel NI, Sehouli J, Fujiwara K, Herzog TJ. Contemporary management of endometrial cancer. Lancet 2012;379(9823):1352-60

16. Sorosky JI. Endometrial cancer. Obstet Gynecol 2012;120 (2 Pt 1):383-97

17. Rathod PS, Shakuntala PN, Pallavi VR. Kundaragi R, Shankaranand B, Vijay CR, Devi KU, Bafna UD. The risk and pattern of pelvic and para aortic lymph nodal metastasis in patients with intermediate and high risk endometrial cancer. Indian J Surg Oncol 2014;5(2):109-14

18. Vargas R, Rauh-Hain JA, Clemmer J, Clark RM, Goodman A, Growdon WB, et. al. Tumor size, depth of invasion and histologic grade as prognostic factors of lymph node involvement in endometrial cancer: a SEER analysis. Gynecol Oncol 2014;133(2):216-20

19. Ozbilen O, Sakarya DK, Bezircioglu I, Kasap B, Yetimalar H, Yigit S. Comparison of myometrial invasion and tumor free distance from uterine serosa in endometrial cancer. Asian Pac J Cancer Prev 2015;16(2) :519-22

20. Rathod PS, Reddihalli PV, Krishnappa S, Devi UK, Bafna UD. A retrospective clinicopathological study of 131 cases with endometrial cancer- is it possible to define the role of retroperitoneal lymphadenectomy in low resource settings? Indian J Cancer 2014;51(1):54-7

21. Pecorelli S. Revised FIGO staging for carcinoma of the vulva, cervix and endometrium. Int $\mathrm{J}$ Gyneacol Obstet 2009;105(2):103-4

22. Creasman WT, Morrow P, Bundy BN, Homesley HD, Graham JE, Heller PB. Surgical pathologic spread pat- 
terns of endometrial cancer. Cancer 1987;60(8 Suppl): 2035-41

23. Euscher E, Fox P, Bassett R, Al-Ghawi H, Ali-Fehmi R, Barbuto D, Djordjevic B. The pattern of myometrial invasion as a predictor of lymph node metastasis or extra uterine disease in low grade endometrial carcinoma. Am J Surg Pathol 2013;37(11):1728-36

24. Frumovitz M, Slomovitz B, Singh DK, Broaddus RR, Abrams J, Sun CC, Bevers M, Bodurka DC. Frozen section analysis as predictors of lymphatic spread in patients with early-stage uterine cancer. J Am Coll Surg 2004;
199(3):388-93

25. Kumar S Mederios F, Dowdy S, Keeney GL, BakkumGamez JN, Podratz KC, Cliby WA, Mariani A. A prospective assessment of the reliability of frozen section to direct intraoperative decision making in endometrial cancer. Gynecol Oncol 2012;127(3):525-31

26. Turan T, Oguz E, Unlubilgin E, Tulunay G, Boran N, Demir OF, Kose MF. Accuracy of frozen section examination for myometrial invasion and grade in endometrial cancer. Eur J Obstet Gynecol Reprod Biol 2013;167(1): 90-5 